\title{
Research into pronunciation learning strategies of pre-service English teachers
}

\author{
Ramazan Yetkin a * \\ a Hacettepe University, Ankara, 06800, Turkey
}

Received 21 July 2017 | Received in revised form 19 September 2017 | Accepted 27 September 2017

\begin{abstract}
Pronunciation, as being one of the core components of a language, plays key roles in language learning and language use. Many studies have already been conducted regarding pronunciation learning and its importance; yet, satisfactory attention has not been given to strategies and strategy use until recently. In line with this objective, this study aims to reveal pronunciation learning strategies of EFL learners in comparison with variables such as gender, age, grade level and years of learning English. A total of 27 pre-service EFL learners took part in the study. A strategic pronunciation learning scale was used to unearth most frequently used strategy types and strategy groups as well as effects of individual variables. Descriptive analysis was used to investigate the results. It was striking to see that there is a significant difference of pronunciation strategy use based on gender, and females use strategies more frequently. Another important factor was to see that even if there is statistically no difference, length of time for learning English can have a positive effect on pronunciation learning strategies.

(C) 2017 EJAL \& the Authors. Published by Eurasian Journal of Applied Linguistics (EJAL). This is an open-access article distributed under the terms and conditions of the Creative Commons Attribution license (CC BY-NC-ND) (http://creativecommons.org/licenses/by-nc-nd/4.0/).
\end{abstract}

Keywords: pronunciation learning strategies, strategy use, gender, age, EFL learners

\section{Introduction}

Over the last decades, there have been a great amount of emphasis on pronunciation, and many research studies have been conducted so far on pronunciation and its relevant aspects (Derwing, Munro, \& Wiebe, 1998; Jones, 1997). One of the prominent aspects of pronunciation is pronunciation learning strategies. Strategies of pronunciation learning have been given little attention to teach specifically, and also quite few, but pivotal studies were undertaken to date exclusively give attention to that aspect, namely to the pronunciation learning strategies (Akyol, 2012; Derwing \& Rossiter, 2002; Hişmanoğlu, 2012; Peterson, 2000; Vitenova \& Miller, 2002).

\footnotetext{
* Ramazan Yetkin. Tel.: +90-312-297-8587

E-mail address: ryetkinn@gmail.com

http://dx.doi.org/......
} 
Strategies of language learning as inclusively defined by Oxford (1990) as "specific action taken by the learner to make learning easier, faster, more enjoyable, more selfdirected, more effective, and more transferable to new situations" (p. 8). Language learning strategies can be taken as an umbrella term for all language relevant aspects of learning, but there are some context- specific needs and differences as they are seen in pronunciation strategies. Pronunciation learning strategies are defined by Peterson (2000) as "the steps taken by students to enhance their own pronunciation learning" (p. 7) and by Hişmanoğlu (2012) as "an attempt to enhance phonetic and phonological competence in the target language" (p. 248). Moreover, Hişmanoğlu (2012) pointed out that "every pronunciation learner utilizes pronunciation learning strategies either deliberately or undeliberately when focusing on segmental and/or supra-segmental phonemes in the target language trying to do tasks given by the teacher in the pronunciation class" (p. 248).

\section{Relevant Literature}

Peterson's (2000) work was the first study exclusively dedicated to pronunciation learning strategies to the best knowledge of the researcher. The participants were 11 adult native- speakers of English taking Spanish course but none of them were from Spanish origin. It was an exploratory study; self-report diaries and interviews were used for data collection. From the analysis of diaries and interview outcomes, 43 tactics, 21 of which were not even in the literature to date, were detected. These tactics were condensed and formed basic 12 pronunciation learning strategies according to Oxford's strategy classifications. The largest number of strategies and tactics was in cognitive part mainly because of its specificity and breadth nature. It was an important and pivotal study because it was the first study to solely focus on pronunciation matter and lead the literature accordingly and by adding many new tactics to the pronunciation learning. However, according to Peterson, there does not seem to be any particular qualitative difference between pronunciation learning strategies and other language learning strategies except that they aid specifically with pronunciation.

Vitenova and Miller (2002) did a pilot study to see their students' needs and hear their voices based on reflective practice. Participants were graduate pronunciation course students who were from different backgrounds, and from diverse language competences. They were asked to reflect their prompts from their pronunciation class. Outcomes unearthed that detailed phonetic/ phonological instruction boosts metacognitive strategies which help learners to employ those strategies in larger communicative contexts. Another important result was that the importance of socioaffective factor in pronunciation learning was understood.

Derwing and Rossiter (2002) carried out a study to examine pronunciation needs and strategies of learners from an adult's perspective. 100 adults from 19 different native language groups, different ages and different proficiency levels participated in the study. Individually designed interviews with statements and questions about 
communication problems faced by participants were conducted over a period of six weeks. It was reported that one third of participants faced with pronunciation difficulties, and they were mostly asked to repeat themselves to be understood with the rate of $37 \%$. It was also reported that paraphrasing was the favorite strategy for dealing with communication cuts. Importantly paraphrasing strategy differs the results of the study from results of similar studies and Oxford's categorization in that respect.

Hişmanoğlu (2012) conducted one of the latest studies on pronunciation learning strategies. Thirty-eight pre-service English teachers participated in the study, and all of them already took a pronunciation specific course. His purpose was to see frequency counts of strategies used by participants based upon Oxford's strategy categorization as well as to see and compare successful and unsuccessful students according to the types of strategies they used and frequencies. A pronunciation strategies questionnaire with 42 items was used and it was revealed that meta-cognitive strategies were used by the majority of participants to improve their pronunciation. Self-evaluation was the most frequently used meta-cognitive strategy. Affective strategies such as using humors to decrease anxiety were also frequently used by participants. Regarding strategy use and frequency of successful and unsuccessful students, it is striking to see that there was no significant difference of strategy use besides meta-cognitive and affective strategies between the two groups.

Similar to Hişmanoğlu's study, Akyol (2012) also conducted a study to see exclusive pronunciation strategy use of Turkish EFL learners. A quasi- experimental study design was used and 82 pre-service English teachers participated in the study. Experiment and control groups were assigned according to whether they took a pronunciation-specific course beforehand. Data were collected through a questionnaire and an interview. Even if the results had many similarities with preceding studies in terms of strategy use (Berkil, 2008; Peterson, 2000), it was interesting to see that participants mostly use cooperative strategy to improve their pronunciation. The most frequently used strategy item also was making association of English pronunciation with Turkish pronunciation. Another striking result was to see that most popular strategies were used by students taking no pronunciation course. She concluded that more emphasis on pronunciation strategy learning and strategy studies should be given to take more steps ahead.

Although few but prominent studies were conducted to date on pronunciation learning strategies, no studies were exclusively conducted to reveal the effect of individual variables on pronunciation learning strategy use. The purpose of this paper is to examine what kind of strategies do learners use while dealing with pronunciation, and what are the effects of individual variables especially on pronunciation strategy use. In this line, following research questions were formulated;

1. Which groups of strategies are used most frequently by the participants?

2. Which are the specific pronunciation strategies used most frequently by the students? 
3. Do male and female students' pronunciation strategy uses differ significantly from each other?

4. Is there a significant difference in students' pronunciation strategy use based on grade level?

5. Is there a significant difference in students' pronunciation strategy use based on years of learning English?

\section{Method}

\subsection{Research Design}

Quantitative research design was applied in order to conduct the research. Pekrun, Goetz, Titz, and Perry (2002) state that "quantitative measures are needed for more rigorous tests of hypotheses" (p. 94). So, a similar approach was preferred in the study to detect the results more meticulously. A total of 28 statements made up of learning experiences presented on the scale and participants' ideas on pronunciation strategy use were gathered by using survey method.

\subsection{Setting and participants}

The current study was conducted at a state university in Ankara, Turkey. Twentyseven students from the English Language Teaching Department of the Hacettepe University took part in this study. The majority of participants were female $(n=21)$ because of the dominance of the female students in language departments. The age range of the participants was between 18 and 23. All grade levels- freshman, sophomore, junior, and senior, were represented in the study. Convenient sampling method was used for the selection of participants and selection process was random in terms of age, gender, grade and years of learning English. All the participants participated voluntarily. Demographic information of participants is shown in Table 1 in detail;

Table 1. Demographic variables and individual differences of the participants

\begin{tabular}{lll}
\hline Variables & $\mathrm{n}$ & $\%$ \\
\hline Age & & \\
18 & 9 & 33.3 \\
19 & 3 & 11.1 \\
20 & 5 & 18.5 \\
21 & 4 & 14.8 \\
22 & 5 & 3.7 \\
23 & 1 & \\
Gender & & 77.8 \\
Female & 21 & 22.2 \\
Male & 6 &
\end{tabular}




$\begin{array}{lll}\text { Grade level } & & \\ \text { Freshman } & 11 & 40.7 \\ \text { Sophomore } & 2 & 7.4 \\ \text { Junior } & 6 & 22.2 \\ \text { Senior } & 8 & 29.6 \\ \text { Years of learning English } & & \\ \text { Less than 10 years } & 14 & 51.9 \\ \text { More than 10 years } & 13 & 48.1 \\ \text { Total } & 27 & 100\end{array}$

\subsection{Data collection}

Strategic pronunciation learning strategies scale (Eckstein, 2007) was used as the main instrument of this study with slight changes. The scale was used to detect the frequency counts of strategy usages of participants while dealing with pronunciation.

The scale was a five-point Likert scale ranging from as never or almost never, usually not (rarely), sometimes, usually and always or almost always. It includes 28 items in total; of all the statements include pronunciation strategies and tactics. The purpose of the scale was to gather frequency counts of pronunciation learning strategies under six activities and seventy-five corresponding strategies. The subcategories were categorized as; input, practice, noticing/feedback, hypothesis testing, hypothesis forming, and motivation.

A web-based survey program was used to collect data. Twenty-seven EFL students participated and return rate was \%100. All the variables, age, gender, grade, and years of learning English, were taken into consideration in data collection process.

\subsection{Data analysis}

After collecting the data, participants' pronunciation learning strategies were investigated by using descriptive statistics. It was decided to use non-parametric tests because of the size of the sample $(n=27)$. First of all, most frequently used strategy categorizations, and specific pronunciation strategies were found out by looking at the mean scores. Then, a Mann-Whitney U test was carried out to examine the differences between females and males in terms of their pronunciation strategy use. Thirdly, a Kruskal Wallis test was applied to find out the differences among grade levels. As a last analysis, a Mann-Whitney $U$ test was conducted to investigate the difference in the length of English learning (less than ten years and more than ten years).

\section{Findings}

\subsection{Which groups of strategies are used most frequently by the participants?}

In order to see the frequency of strategy groupings by the participants, descriptive statistics were used and mean values and standard deviation were provided. 
Table 2. Mean values of used strategy groups

\begin{tabular}{llll}
\hline Groups of Strategies & N & Mean & SD \\
\hline Hypothesis Testing & 27 & 3.82 & .71 \\
Input & 27 & 3.57 & .7 \\
Motivation & 27 & 3.56 & .71 \\
Hypothesis Forming & 27 & 3.55 & .7 \\
Practice & 27 & 3.42 & .79 \\
Noticing / feedback & 27 & 3.22 & .82 \\
\hline
\end{tabular}

As displayed at the table above, the mean values of strategy groups are ranging from 3.22 to 3.82. Even if there are similar values among all the strategy groupings, it was seen that hypothesis testing strategies were used most frequently as a pronunciation learning strategies by the participants $(M=3.82 S D=.71)$. Even if input and motivation strategy groupings had similar mean values, input strategies come in second after hypothesis testing $(M=3.57 S D=.7)$.

4.2. Which are the specific pronunciation strategies used most frequently by the students?

The mean values and standard deviations were calculated with descriptive statistics to find out which strategy was used mostly by the participants.

Table 3. Which are the specific pronunciation strategies used most frequently by the students?

\begin{tabular}{llll}
\hline Strategies & $\mathrm{N}$ & Mean & $\mathrm{SD}$ \\
\hline S27 & 27 & 4.11 &, 847 \\
S16 & 27 & 4.11 &, 934 \\
S15 & 27 & 3.96 & 1,091 \\
S13 & 27 & 3.96 & 1,055 \\
S22 & 27 & 3.89 & 1,013 \\
S19 & 27 & 3.85 &, 770 \\
S2 & 27 & 3.85 &, 949 \\
S20 & 27 & 3.81 &, 921 \\
S21 & 27 & 3.74 & 1.023 \\
S6 & 27 & 3.74 & .859 \\
S28 & 27 & 3.67 & 1.074 \\
S7 & 27 & 3.67 & 1.074 \\
S3 & 27 \\
S17 & 27 & 3.63 & .742 \\
S1 & 27 & 3.59 & 1.010 \\
S23 & 27 & 3.59 & .971 \\
S14 & 27 & 3.56 & 1.050 \\
S24 & 27 & 3.44 & 1.311 \\
S26 & 27 & 3.41 & 1.010 \\
S25 & 27 & 3.30 & .912 \\
& 27 & 3.30 & .953
\end{tabular}




\begin{tabular}{llll} 
S8 & 27 & 3.26 & 1.318 \\
S9 & 27 & 3.22 & .974 \\
S4 & 27 & 3.22 & 1.086 \\
S10 & 27 & 3.19 & 1.302 \\
S5 & 27 & 3.00 & 1.271 \\
S11 & 27 & 2.93 & 1.328 \\
S12 & 27 & 2.81 & 1.302 \\
S18 & 27 & 2.63 & 1.115 \\
\hline
\end{tabular}

As demonstrated at the table above, pronunciation learning strategies numbered S27 (When I study English pronunciation, I look for a good environment.) and S16 (When I find a word I don't know how to pronounce, I am willing to guess the pronunciation) were mostly used by students when they had problems with their pronunciation $(\mathrm{S} 27 \mathrm{M}=4.11, \mathrm{SD}=.847 ; \mathrm{S} 16 \mathrm{M}=4.11, \mathrm{SD}=.934)$

4.3. Do male and female students' pronunciation strategy uses differ significantly from each other?

The differences of male and female participants regarding pronunciation strategy use were investigated with a Mann-Whitney U test.

Table 4. Difference between female and male students' pronunciation strategy use

\begin{tabular}{lllllllll}
\hline & Female & \multicolumn{3}{c}{ Male } & & & \\
$\mathrm{n}$ & Mean Rank & $\begin{array}{l}\text { Sum of } \\
\text { Ranks }\end{array}$ & $\mathrm{n}$ & Mean Rank & $\begin{array}{l}\text { Sum of } \\
\text { Ranks }\end{array}$ & $\mathrm{U}$ & $\mathrm{z}$ & $\mathrm{p}$ \\
\hline 21 & 15.79 & 331.50 & 6 & 7.75 & 46.50 & 25.500 & -2.190 & .029 \\
\hline
\end{tabular}

As displayed in Table 4, it was revealed that there is a significant difference between female and male students' pronunciation strategy use; female students $(M D$ $=3.65, n=21)$ and male students $(M D=3.12, n=6), U=25.500, z=-2.190, p=.029$. It was understood that female students outweigh male students in pronunciation strategy use.

4.4. Is there a significant difference in students' pronunciation strategy use based on grade level?

The differences of pronunciation strategy use by participants according to their grade revel were examined by using a Kruskal Wallis test.

Table 5. Grade level and pronunciation strategy use difference

\begin{tabular}{llllll}
\hline Level of Success & $\mathrm{n}$ & $\mathrm{MD}$ & Mean Rank & $\chi^{2}$ & $\mathrm{df}$ \\
\hline Freshman & 11 & 3.54 & 12.73 & 2.166 & 3 \\
Sophomore & 2 & 3.64 & 11.75 & & \\
Junior & 6 & 3.25 & 11.58 & &
\end{tabular}


Senior $\quad \begin{array}{lll}8 & 3.55 & 16.63\end{array}$

As it is clear from Table 5, the Kruskal-Wallis Test revealed no significant difference in pronunciation strategy use according to grade levels; freshman $(M D=$ $3.54, n=11)$, sophomore $(M D=3.64, n=2)$, junior $(M D=3.25, n=6)$, and senior $(M D$ $=3.55, n=8) ; X^{2}(2,166)=3, p=.539$.

4.5. Is there a significant difference in students' pronunciation strategy use based on years of learning English?

The length of learning English and its implications for pronunciation strategy use were also investigated via Mann-Whitney U test.

Table 6. Years of learning English and pronunciation strategy use

\begin{tabular}{lllllllll}
\hline & \multicolumn{1}{c}{ Less than 10 years } & \multicolumn{7}{c}{ More than 10 years } \\
$\mathrm{n}$ & Mean Rank & $\begin{array}{l}\text { Sum of } \\
\text { Ranks }\end{array}$ & $\mathrm{n}$ & Mean Rank & Sum of Ranks & $\mathrm{U}$ & $\mathrm{z}$ & $\mathrm{p}$ \\
\hline 14 & 13.00 & 182.00 & 13 & 15.08 & 196.00 & 77.000 & -.680 & .496 \\
\hline
\end{tabular}

As revealed in Table 6 , it was understood that there is no significant difference regarding students' years of learning English; less than ten years $(M D=3$. 39, $n=14)$ and more than ten years $(M D=3.64, n=13), U=25.500, z=-2.190, p=.029$. Students with more than ten years of English experience showed more frequent strategy use $(M d .=3.64)$, even if it is not statistically different.

\section{Discussion and Conclusions}

Although pronunciation is one of the core areas of learning, pronunciation learning strategies were ignored till 2000. Peterson (2000) conducted the first study in the on pronunciation strategies and leaded the literature (Akyol, 2012; Derwing \& Rossiter, 2002; Eckstein, 2007; Hişmanoğlu, 2012; Vitenova \& Miller, 2002).

This present study aims to reveal pronunciation learning strategy use of participants and effect of variables such as age, gender, grade levels, and years of learning English on pronunciation strategy use. Firstly, it was found out that gender has a significant effect on pronunciation strategy use. None of the previous studies revealed the effect of gender on pronunciation strategy use, but this paper unearthed that there is a significant deference between females and males and females outweighs males in strategy use.

Secondly, it was seen that hypothesis testing strategies (correcting/clarifying self, avoiding frustration, circumlocution, altering volume or speed of speech) were used by participants mostly. As a specific strategy and tactic, it was interesting to see that participants mostly either look for a good environment or try to guess the pronunciation as most frequent strategy type(s). These results can be linked to previous studies in the literature. Akyol (2012) similarly found out that participants mostly preferred to use cooperation strategy (can be linked to good environment) and 
memory strategies (can be linked to guess the pronunciation). Moreover, Derwing and Rossiter (2002) detected that participants were eager to use self repetition and volume adjustment as their common strategy when they did not understand.

Lastly, participants grade level and years of learning English were investigated to reveal possible effects of these variables on pronunciation strategy use. Although statistically no significant difference was found out, it was understood that years of learning English has a positive effect on pronunciation strategy use. This can be explained by experience. Hişmanoğlu (2012) unearthed metacognitive strategies as mostly used group. In this line, it can be said that the more experienced the learners are, the more strategy types they will benefit such as self- evaluation.

All in all, it was revealed in this study that gender has a significant effect on pronunciation learning strategy use. Although age and grade level of participants make no difference, length of time for English learning can have a positive effect on pronunciation strategy use.

\section{References}

Akyol, T. (2013). A study on identifying pronunciation learning strategies of Turkish EFL learners. Procedia Social and Behavioral Sciences, 70, 1456-1462. doi: 10.1016/j.sbspro.2013.01.211

Derwing, T. M., Munro, M. J., \& Wiebe, G. (1998). Evidence in favor of a broad framework for pronunciation instruction. Language Learning, 48(3), 393-410. doi: 10.1111/00238333.00047

Derwing, T. M., \& Rossiter, M. J. (2002). ESL learners' perceptions of their pronunciation needs and strategies. System, 30, 155-166. doi: 10.1016/S0346-251X(02)00012-X

Eckstein, G. T. (2007). A correlation of pronunciation learning strategies with spontaneous English pronunciation of adult ESL learners. Unpublished Master's Thesis, Brigham Young University Department of Linguistics and English Language, Provo.

Hişmanoğlu, M. (2012). An investigation of pronunciation learning strategies of advanced EFL learners. Hacettepe Üniversitesi Eğitim Fakültesi Dergisi, 43, 246-257.

Jones, R. H. (1997). Beyond "listen and repeat": Pronunciation teaching materials and theories of second language acquisition. System, 25(1), 103-112. doi: 10.1016/S0346-251X(96)00064-4

Oxford, R. (1990). Language learning strategies: What every teacher should know. New York, NY: Newbury House.

Pekrun, R., Goetz, T., Titz, W., \& Perry, R. P. (2002). Academic emotions in students' self regulated learning and achievement: A program of qualitative and quantitative research. Educational Psychologist, 37(2), 91-105.

Peterson, S. S. (2000). Pronunciation learning strategies: A first look. Retrieved from the Eric database. (ED495903)

Vitanova, G., \& Miller, A. (2002). Reflective practice in pronunciation learning. The Internet TESL Journal, 8(1). Retrieved Decemcer 1, 2015, from http://iteslj.org.

\section{Copyrights}

Copyright for this article is retained by the author(s), with first publication rights granted to the Journal.

This is an open-access article distributed under the terms and conditions of the Creative Commons Attribution license (CC BY-NC-ND) (http://creativecommons.org/licenses/by-nc-nd/4.0/). 